\title{
Tobacco-Specific Nitrosamines in the Tobacco and Mainstream Smoke of U.S. Commercial Cigarettes
}

\author{
Selvin H. Edwards ${ }^{\dagger}$, Lana M. Rossiter ${ }^{\dagger}$, Kenneth M. Taylor ${ }^{\dagger,}{ }^{,}$, Matthew R. Holman ${ }^{\dagger}$, Liqin \\ Zhang $^{\ddagger}$, Yan S. Ding ${ }^{\ddagger}$, and Clifford H. Watson ${ }^{\ddagger}$ \\ †Center for Tobacco Products, Food and Drug Administration, Silver Spring, MD, USA, 20850 \\ $\ddagger$ Centers for Disease Control and Prevention, National Center for Environmental Health, Atlanta, \\ $\mathrm{GA}, 30341$
}

\section{Abstract}

Tobacco-specific nitrosamines (TSNAs) are N-nitroso-derivatives of pyridine-alkaloids (e.g., nicotine) present in tobacco and cigarette smoke. Two TSNAs, N'-nitrosonornicotine (NNN) and 4-(methylnitrosamino)-1-(3-pyridyl)-1-butanone (NNK), are included on the Food and Drug Administration's list of harmful and potentially harmful constituents (HPHCs) in tobacco products and tobacco. The amounts of four TSNAs (NNK, NNN, N-nitrosoanabasine (NAB), and N'nitrosoanatabine (NAT)) in the tobacco and mainstream smoke from 50 U.S. commercial cigarette brands were measured from November 15, 2011 to January 4, 2012 using a validated, HPLCMS/MS method. Smoke samples were generated using the International Organization of Standardization (ISO) and Canadian Intense (CI) machine-smoking regimens. NNN and NAT were the most abundant TSNAs in tobacco filler and smoke across all cigarette brands whereas NNK and NAB were present in the least amounts. The average of the ratios for each TSNA in mainstream smoke to filler content is $29 \%$ by the CI smoking regimen and $13 \%$ for the ISO machine-smoking regimen. The reliability of each TSNA to predict total TSNA amounts in the filler and smoke was examined. NNN, NAT, and NAB have a moderate to high correlation $\left(\mathrm{R}^{2}=\right.$ $0.61-0.98)$ and all three TSNAs individually predict total TSNAs with minimal difference between measured and predicted total TSNA amounts (error $<7.4 \%$ ). NNK has weaker correlation $\left(\mathrm{R}^{2}=0.56-0.82\right)$ and is a less reliable predictor of total TSNA quantities. Tobacco weight and levels of TSNAs in filler influence TSNA levels in smoke from the CI machine-smoking regimen. In contrast, filter ventilation is a major determinant of levels of TSNAs in smoke by the ISO machine-smoking regimen. Comparative analysis demonstrates substantial variability in TSNA

\footnotetext{
* Corresponding Author Kenneth M. Taylor, Office of Science, Center for Tobacco Products, US Food and Drug Administration, 10903 New Hampshire Avenue, Building 32, Silver Spring, MD 20993, USA. Telephone: 301-796-8311; Fax: 301-595-1435; Kenneth.Taylor@fda.hhs.gov. S-1); Correlation Coefficients and associated 95\% Confidence Limits of TSNAs in tobacco (Table S-2); Correlation Coefficients and associated 95\% Confidence Limits of TSNAs in smoke by ISO smoking regimen (Table S-3); Correlation Coefficients and associated 95\% Confidence Limits of TSNAs in smoke by CI smoking regimen (Table S-4); transfer efficiency for commercial cigarette brands in ISO and CI mainstream cigarette smoke (Figure S-1). This material is available free of charge via the internet at https://pubs.acs.org. DISCLAIMER

The findings and conclusions of this report are those of the authors and do not necessarily represent FDA and CDC positions or policies.
} 
amounts in tobacco filler and mainstream smoke yields under ISO and CI machine smoking regimens among U.S. commercial cigarette brands.

\section{Keywords}

ISO smoking regimen; TSNAs; cigarette smoke; Canadian Intense smoking regimen; NNK; NNN

\section{INTRODUCTION}

Cigarettes are the most prevalent combusted tobacco products consumed worldwide. ${ }^{1}$ In the U.S., the rise in cigarette smoking rates resulted in a steady increase in lung cancer incidence and mortality in both men and women. Trends show that since the mid1990s, mortality rates attributable to lung cancer declined significantly in men but continue to increase in women. ${ }^{1,2}$ Lung cancer was one of the first diseases to be causally linked with tobacco smoking, which is the principal cause of this disease. ${ }^{3}$ Several scientific studies have identified a few organ-specific, mutagenic cigarette-smoke constituents that initiated lung cancer tumors in laboratory animals. ${ }^{4-12}$ Cigarette smoke itself is a complex composite containing numerous carcinogens, including several tobacco-specific nitrosamines (TSNAs). ${ }^{5,13}$ Several TSNAs cause tobacco-related carcinogenesis. ${ }^{14}$ Obtaining a better understanding of these constituents in tobacco filler and smoke for a broad variety of U.S. domestic cigarettes can provide an insight into the variation of TSNA amounts among cigarette products and their related toxicity. In addition, measuring TSNAs in cigarette products can reveal influential factors affecting the efficiency of TSNA transfer from tobacco filler to smoke, and the potential exposure risk from smoking.

TSNAs are naturally present in fresh green tobacco and increases during curing, storage, fermentation, and processing of harvested tobacco leaves. ${ }^{15-17}$ They are nitrosation products of endogenous pyridine alkaloids like nicotine and nornicotine. N'-nitrosonornicotine (NNN), 4-(methylnitrosamino)-1-(3-pyridyl)-1-butanone (NNK), N'-nitrosoanatabine (NAT) and N'-nitrosoanabasine (NAB) are the most commonly studied TSNAs (Figure 1). NNN and NNK are potent carcinogenic TSNAs and their role in induction of several malignancies, including lung, esophageal, and pancreatic cancers in laboratory animals is welldocumented. ${ }^{7-9,} 11,18$ Because of sufficient evidence in experimental animals, NNN and NNK are classified as carcinogenic to humans (Group 1) by the International Agency for Research on Cancer. ${ }^{19}$ In addition , the U.S. Food and Drug Administration (FDA) has included NNN and NNK on the list of harmful and potentially harmful constituents (HPHCs) in tobacco and cigarette smoke ${ }^{20}$ and tobacco product manufacturers are required to test and report the quantities in their cigarette products. In contrast, NAB is weakly carcinogenic while NAT has no carcinogenic properties and neither have been designated as HPHCs. ${ }^{19}$

The occurrence of TSNAs in tobacco filler and mainstream smoke of commercial cigarettes is well-documented. ${ }^{21,22}$ Before mandatory HPHC reporting requirements for tobacco and smoke, information on TSNA amounts in U.S., commercial cigarettes were gathered largely from independent research studies. ${ }^{23-26}$ These studies focus primarily on understanding 
differences in smoke yields among a variety of domestic brands as well as comparison to international commercial cigarette products. Wu et al. studied smoke yields of NNN and NNK in Marlboro and popular domestic brands from 14 different countries. The summed quantities of NNN and NNK levels in this study ranged from 8.7 to $341 \mathrm{ng} /$ cigarette. Both U.S. and local Marlboro brands and the U.S. domestic Doral brand has approximately 2-fold higher TSNAs than the corresponding local brands in those countries. ${ }^{26}$ Similarly, Fisher et al. 24,27 examined TSNA levels in American Blend cigarette products compared to several local Canadian and German filtered cigarette brands, manufactured with local blended or single Virginia flue-cured tobacco varieties. The TSNA levels in U.S. style cigarettes containing an American blend of tobaccos was approximately 2 -fold greater than amounts in the other products. Throughout these brand comparison studies, smoke collection by the International Organization for Standards (ISO) machine-smoking protocol was most widely reported, $1,5,23,24,28-32$ despite its limitation to not represent actual human smoking behavior and corresponding potential exposure to harmful constituents. ${ }^{1}$ For this reason, the World Health Organization's Study Group on Tobacco Product Regulation (TobReg) recommends testing cigarettes by more than one machine-smoking regimen, specifically the ISO and Canadian Intense (CI) machine-smoking regimens, for product and testing protocol comparison studies, and to better approximate the range of constituent yields that a cigarette is capable of producing ${ }^{33,34}$ Despite this recommendation, few studies compare TSNA smoke deliveries for the same U.S. cigarette products for both ISO and CI machine-smoking regimens. ${ }^{25}$ Based on the previous studies, variation in the TSNAs mainstream smoke deliveries could likely result from differing product characteristics and smoking conditions.

A few important sources of variation in TSNA levels in smoke that are often not considered in cigarette product comparisons are the corresponding amount of TSNAs in the tobacco filler and the transfer efficiency of these TSNAs from the filler to smoke. Agronomic, environmental, and postharvest tobacco curing and processing methods affect levels of TSNAs in tobacco filler ${ }^{16,35}$ Thus, variations in these conditions as well as blending of various types of tobaccos can cause considerable differences in filler TSNA amounts and subsequently the amounts in smoke. Additionally, scientific evidence suggests that 30 to $50 \%$ of NNN and NNK in machine-generated mainstream smoke is due to transfer from the tobacco filler to smoke during combustion ${ }^{36-39}$ and such studies have led to claims of a proportional relationship between TSNAs in both tobacco filler and mainstream smoke. ${ }^{25,26}$ The feasibility of testing for these nitrosamines in both tobacco filler and smoke of the same products, for comparative product analysis, has been formally demonstrated. ${ }^{25}$ However, only limited information on TSNAs in tobacco filler or reference to their transfer efficiency from filler to smoke of U.S. commercial filtered cigarettes have been reported. ${ }^{25}$ In the present study, the amounts of TSNAs in the tobacco filler and in the mainstream smoke from a variety of US commercial filtered cigarettes are measured. Brand specific TSNA content and emissions are compared to assess which product attributes affect TSNA transfer efficiency from tobacco filler to smoke. In addition, linear regression analysis of individual and total TSNA amounts was performed to determine if the amount of total TSNAs in tobacco and tobacco smoke could be predicted using a simple model. To our knowledge this is the first comprehensive assessment of TSNA amounts and transfer efficiency of all four 
TSNAs in tobacco filler and smoke, by two smoking regimens, for a broad variety of domestic cigarette brands.

\section{MATERIALS AND METHODS}

\section{Reagents and Chemicals}

All four TSNAs and their isotopically labeled analogues were purchased from Cambridge Isotope Laboratories. Acetonitrile, acetone, and cyclohexane were obtained from Sigma and were high-performance liquid chromatography (HPLC) grade. Cambridge filter pads (CFP) (44 mm glass-fiber filter pad) were obtained from Whatman (Maidstone, United Kingdom).

\section{Cigarette Selection}

All commercial filtered cigarette products for this study were purchased from retail stores in the metropolitan Atlanta Georgia area in 2011. Selected brands were chosen based on U.S. cigarette market share in 2010. The selected cigarettes include 35 popular brands, which accounted for approximately $54 \%$ of the total cigarette market sales from major manufacturers, and 15 less popular brands with lower market share. The cigarettes were regular, menthol, or Turkish flavored, and all contained a cellulose acetate filter. The cigarette products exhibited a wide range of physical attributes including filter length, paper porosity, ventilation, and tobacco weight. The variety of products represented several brand variants from five major tobacco product manufacturers (Supporting Information Table S-1). Samples were assigned unique identification numbers and logged into a database for tracking purposes. The 2R4F and 3R4F research cigarettes were obtained from the University of Kentucky's, Kentucky Tobacco Research and Development Center (Lexington, $\mathrm{KY})$. All cigarettes were stored in their original packaging at $-80^{\circ} \mathrm{C}$ until analysis from November 15, 2011 to January 4, 2012 .

\section{Extraction of TSNAs from tobacco filler}

Tobacco filler from individual cigarette was removed from the paper wrapper and ground with a coffee grinder (Saahi model SA-1440) until the tobacco is a fine power-like consistency. For each cigarette type, seven 0.25 -g samples were measured. Each 0.25 -g sample was spiked with 13C-labeled TSNA internal standard solution, and mixed with 10 $\mathrm{mL}$ of $100-\mathrm{mM}$ ammonium acetate solution. The mixture was then prepared as described below for the smoke TSNA extraction and HPLC tandem mass spectrometry analysis. The result of TSNAs in tobacco filler was reported as nanogram (ng) individual TSNA per-gram tobacco.

\section{Extraction of TSNAs from mainstream smoke}

Mainstream Smoke Collection-Cigarettes were machine smoked according to ISO (60-s puff interval, 2-s puff duration, $35 \mathrm{~mL}$ puff volumne, unblocked ventilation) ${ }^{40}$ and CI (30-s puff interval, 2-s puff duration, $55 \mathrm{~mL}$ puff volume, $100 \%$ blocked ventilation) machine smoking regimens. ${ }^{41}$ All cigarettes and CFPs were conditioned for at least $24 \mathrm{~h}$ at $22^{\circ} \mathrm{C}$ and $60 \%$ relative humidity. ${ }^{31,42}$ Cigarette machine-smoking was performed on a Cerulean ASM500 16-port smoking machine (Milton Keynes, United Kingdom). The cigarettes were smoked to a butt length of $23 \mathrm{~mm}$ or the length of the filter overwrap plus 3 
$\mathrm{mm}$, whichever was longer. One cigarette was smoked per CFP for each cigarette sample. During each smoking run, Kentucky Research 2R4F (University of Kentucky) research cigarettes were smoked as quality-control samples.

Extraction of TSNAs from CFPs-The sample preparation and LC/MS/MS analysis procedures were based on a previously published method. ${ }^{31,42}$ After smoking, each CFP was spiked with $\left[{ }^{13} \mathrm{C}_{6}\right]$-labeled TSNA internal standard solution and extracted with $10 \mathrm{ml}$ of 100-mM ammonium acetate solution by shaking on a Lab-line shaker operated at $250 \mathrm{rpm}$ for $1 \mathrm{~h}$. A 1-ml aliquot was placed in a 2-ml amber vial for analysis. The sample vials were loaded on the auto-sampler where $20 \mu \mathrm{L}$ were injected into an Agilent Technologies 1100 HPLC coupled with an API 4000 triple-quadruple mass spectrometer (Applied Biosystems; HPLC-tandem mass spectrometry (MS/MS)] to analyze TSNAs. The HPLC column selection and MS/MS variables were described previously. 26,42 The result of TSNAs in mainstream smoke was reported as ng individual TSNA per cigarette. The averages are based on seven replicate measurements for each cigarette product.

Statistical Analysis-Statistical analysis was performed with SAS statistical software package (SAS institute, Inc., Cary NC) to perform multiple regression and analysis and to determine correlation coefficient ( $\mathrm{r}$ ) and $95 \%$ confidence intervals of the correlation coefficients. The TSNA data did not adhere to a normal distribution; therefore, we used the Spearman Ranked correlation coefficients. All correlation coefficients were statistically significant if the span of the $95 \%$ Confidence Limits excluded zero and significance p-value was less than 0.05 . The results for the individual and total TSNA amounts in an exploratory sample of 30 commercial cigarettes, with total TSNA amounts spanning the range of quantities for all of the cigarettes tested was used to derive best-fit linear regression models. The regression model was validated using TSNA measurements for a validation set of cigarette products.

Quality Control Assessment-For quality control, 2R4F Kentucky Research cigarettes were included in each smoke and analytical run with the commercial cigarettes for smoke TSNAs. 3R4F filler was analyzed in each run for tobacco filler TSNAs. The 2R4F and 3R4F research cigarettes are constructed to represent typical American blended cigarettes consisting of mainly Bright, Burley, Oriental, and Reconstituted tobaccos.

\section{RESULTS}

Levels of all four TSNAs in mainstream smoke of the $2 \mathrm{R} 4 \mathrm{~F}$ and in tobacco filler of the $3 \mathrm{R} 4 \mathrm{~F}$ research cigarettes were within the range of values reported previously. ${ }^{43}$ The average imprecision (reported as percent coefficient of variation (\% CV)) for tobacco filler measurements was $4.2 \%$ for $3 \mathrm{R} 4 \mathrm{~F}$ and the average for commercial cigarettes was $4.4 \%$. The average imprecision for the $2 \mathrm{R} 4 \mathrm{~F}$ smoke analysis were $8.4 \%$ and $9.3 \%$ for the ISO and CI machine-smoking regimens, respectively. Imprecision for the commercial cigarettes were $12.2 \%$, and $11.5 \%$ on average for ISO and CI machine-smoking regimen, respectively (Table 2 and 3$)$. 


\section{TSNAs in Tobacco Filler of Commercial Cigarettes}

Table 1 summarizes average amounts and standard deviations for all four TSNAs in unburned tobacco filler of all examined cigarettes. The amounts of all four TSNAs vary widely among the cigarettes. The median (range) amounts of NNN in tobacco filler is 1945 (306 - 2970); NAT is 1461 (320 - 1876; NNK is 498 (194 - 1093) and NAB is 75 (21 - 92) $\mathrm{ng} / \mathrm{g}$ of tobacco. The total TSNA amounts in filler of all the cigarettes, obtained as the summation of quantities of NNN, NAT, NNK, and NAB, ranges from 841 to $5590 \mathrm{ng} / \mathrm{g}$, tobacco. As shown in Table 1, American Spirit Blue, HP (the only cigarette brand containing $100 \%$ flue-cured tobacco) exhibits lowest total TSNA. However, among the American blend cigarette products, Maverick Gold 100s, HP was the next lowest cigarette brand. In contrast, total TSNA amount are highest for the Doral Gold, HP, and is approximately 8-fold more than amounts in American Spirit Blue, HP. NNN amounts differ by nearly 10-fold between the lowest and highest-ranking cigarette products whereas NAT, NNK, and NAB differs by approximately 5 -fold between lowest and highest ranking cigarette products.

\section{TSNAs in Mainstream Smoke under ISO Machine-Smoking Regimen}

Table 2 summarizes the average amounts of all four TSNAs in smoke particulate collected by ISO machine smoking regimen. As shown, TSNA yields vary widely among the commercial cigarettes analyzed. The median (range) smoke deliveries of NNN is 80 (18$171)$; NAT is $85(19-145)$; NAB is $12(4-22)$; and NNK is 55 (13-122), ng/cigarette. NNN, NNK and NAT amounts between the lowest and highest yielding cigarette products differ by 8 -fold while NAB amount differs by less than 5-fold. Total TSNA amounts in the smoke of all cigarette products ranged from 55 to 461, ng/cigarette, which represents an 8fold difference between the lowest and highest-ranking cigarette brands. Among American blend cigarette products, total TSNA smoke yield is the lowest for Carlton White 100s, HP and the highest for Winston Red 100s, HP despite a relative ranking $36^{\text {th }}$ and $45^{\text {th }}$ with respect to increasing TSNA content in tobacco filler. In addition, when smoking by the ISO smoking regimen Doral Gold, HP ranks $25^{\text {th }}$ highest among all cigarette brands for total TSNA deliveries in mainstream smoke, despite having the highest total TSNA amounts in tobacco filler. Whereas American Spirit Blue, HP exhibits marginally higher amounts of NNK than NNN, all of the remaining 49 cigarette brands displayed higher NNN than NNK amounts in smoke.

\section{TSNAs in Mainstream Smoke under $\mathrm{Cl}$ Machine-Smoking Regimen}

Table 3 summarizes the average CI smoke yields of four TSNAs. The amount of all four TSNAs in smoke varies widely for the commercial cigarettes. TSNA yield averages are approximately 2.5 -fold greater for CI smoking yields than that observed with ISO machinesmoking regimen. For the CI regimen the median (range) smoke deliveries of NNN is 186 (33- 323), ng/cigarette; NAT is 183 (44-292); NNK is 118 (40-246); and NAB is 26 (741), ng/cigarette. Total TSNA smoke yields range from 124 to 902, ng/cigarette. The difference in total TSNA amounts between the lowest and highest-ranking cigarette brands is approximately 7-fold. American Spirit Blue, HP exhibits the lowest total TSNA smoke yield, which is consistent with the observations for tobacco filler and ISO machine smoking regimen. However, this product also has higher amounts of NNK than NNN in smoke. 
Among all American blend cigarette products, Salem Silver 100s, HP has the lowest total TSNA CI machine-smoke delivery. In contrast, consistent with observations for the ISO machine-smoking regimen, Winston Red 100s, HP ranks among cigarette brands with the highest total TSNA smoke yields and exhibits higher NNN quantities than NNK amounts. Doral Gold HP, has the $7^{\text {th }}$ lowest total TSNA smoke yields by the CI machine-smoking regimen despite ranking among $29^{\text {th }}$ highest by ISO machine-smoking regimen and having the highest amounts in filler.

\section{Transfer Efficiency of TSNAs between Filler and Mainstream Smoke}

Figure 2 depicts average transfer of TSNAs from unburned tobacco filler to mainstream smoke. To obtain the transfer efficiency, which is relative ratio of the amount of TSNAs in the filler to the resulting amount measured in smoke (where the contribution to mainstream TSNA smoke levels arises from direct transfer from the tobacco filler and pyro-synthesis resulting from various combustion processes), the tobacco filler TSNA amounts were normalized with respect to the average tobacco weight in the cigarette rod. NNN and NAT exhibit the lowest transfer efficiency under both ISO and CI smoking regimens, even though they are the most abundant TSNAs in tobacco filler. When smoking by ISO smoking regimen, NNN and NAT have average transfer of approximately $7 \%$ while NAB and NNK have average transfer efficiency of nearly $20 \%$. The average transfer for all four TSNAs was $13 \%$. The transfer efficiency of total TSNAs from filler to smoke was lowest for Carlton White 100s, HP (2\%) and highest for Winston Red 100, HP (12\%). (Supporting information Figure S-1A)

In contrast, when smoking cigarettes according to the CI smoking regimen, NNN and NAT have average transfer of approximately $18 \%$ while the average for NAB and NNK was nearly $43 \%$. The average transfer of all four TSNAs was approximately $29 \%$ for all products. The transfer efficiency of total TSNAs from filler to smoke was lowest for Doral Gold, HP (13\%) and highest for Capri Magenta SS, HP (31\%). Although Winston Red 100s, HP has the highest yield of NNN and NNK in smoke by the ISO smoking regimen, the transfer efficiency from filler to smoke observed for Winston Red 100s, HP was marginally lower than the observation for Capri Magenta SS, HP (Supporting information Figure S-1B). The transfer efficiency for American Spirit Blue, HP and Carlton White 100s, HP falls in the mid-range of the data set despite having the lowest amounts of TSNAs in tobacco filler and smoke for all cigarette brands tested.

\section{Correlation of Individual and Total TSNA Amounts}

We analyzed correlations among the four individual TSNAs and with the total TSNA amounts in tobacco filler. Tobacco filler exhibits very weak to moderate correlation among all four individual TSNAs (Supporting Information Table S-3). NNK exhibits weakest association with NNN and NAT $(r=0.38)$, whereas correlation was strongest for NAT and NAB $(r=0.79)$. Overall, the correlation coefficients of all four TSNAs with total TSNA amounts in tobacco filler ranged from 0.68 to 0.94 (Supporting Information Table S-2). Similarly, we examined correlations when smoking the cigarettes by the ISO machinesmoking regimen. All four TSNAs exhibit moderate to strong correlations among themselves and with total TSNA quantities. NNK had moderate correlation with NNN and 
NAT $(r=0.86)$. In contrast, correlation was strongest for NNN with NAT $(r=0.95)$ and with NAB $(r=0.96)$. Under standard ISO smoking, all four TSNAs display very strong correlations with total TSNA quantities in smoke. The correlation coefficients for the association individual TSNA amounts and total TSNA amounts ranged from 0.93 to 0.99 . Similarly, when smoking the cigarettes by the CI machine-smoking regimen, all four TSNAs exhibit moderate to strong correlation among themselves and with total TSNA amounts. Consistent with the observations for TSNAs in tobacco filler, correlations were weakest for NNK. All correlations coefficients for NNK associations ranged from 0.60 to 0.75 . In contrast, correlations were strongest for NNN, NAT, and NAB among themselves and with total TSNA amounts in smoke. All correlation coefficients for NNN, NAT, and NAB with total TSNA amounts were greater than 0.92 (Supporting Information Table S-4).

Figure 3 (A-C) displays linear association of all four TSNAs with total TSNA amounts in tobacco filler and in smoke by ISO and CI smoking regimens for an exploratory subset of the commercial cigarettes. Table 4 summarizes Pearson's coefficients of determination and the mean \%DIFF between the sum of measured TSNA quantities and predicted total TSNA amounts for the validation products. Overall, absolute \%DIFF was less than 3\% for TSNAs in tobacco and less than $8 \%$ for TSNAs in mainstream smoke. The \%DIFF ranged from -2.6 to $0.2 \%$ for predicted total TSNA amounts in tobacco filler. Similarly, the \%DIFF ranged from -0.3 to $7.4 \%$ and 1.9 to $4.6 \%$ for predicted total TSNA amounts by the ISO and CI machine-smoking regimens, respectively.

\section{DISCUSSION}

Increases in rates of lung cancer among smokers in the US are attributed to changes in cigarette design and tobacco composition, including TSNAs. ${ }^{2,}{ }^{44}$ This raises the possibility that there may be a difference in exposure risk for smokers of different cigarette brands. It has been suggested that cigarette manufacturers design their products to control smoke deliveries and to reduce smoke level exposure to carcinogenic chemical constituents such as TSNAs. ${ }^{45}$ However, information needed to readily compare TSNA amounts in tobacco filler and in smoke of a large variety of US commercial cigarettes by both ISO and CI machinesmoking regimens is scarce. For these reasons, we conducted this survey to assess variations of NNN, NNK, NAT, and NAB quantities in filler and smoke matrices of a large variety of U.S. commercial cigarette products as this potentially has implications for exposure to TSNAs while using these products.

The results of this survey show substantively different levels of commonly measured TSNAs in tobacco filler across a large variety of domestic cigarette products. As indicated by the results for the $3 \mathrm{R} 4 \mathrm{~F}$ research cigarette, analytical contribution to the variation in TSNA amounts in the products tested is minimal. The results for the commercial cigarettes are considerably lower than amounts reported by Counts et al. ${ }^{30}$ for 26 conventional commercial cigarette products, sampled at production sites and purchased at retail outlets in 2002, that were examined to develop a "market map' comparison method to evaluate new and nonconventional cigarettes. Counts corrected the TSNA results for the moisture content in the tobacco filler, whereas the results reported herein did not. However, the mean quantities of all four TSNAs and the total TSNA content across all of the cigarettes tested in the current 
study were virtually identical to the results reported by Stepanov et al. ${ }^{25}$ for tobacco filler TSNAs in several U.S. cigarette brands purchased in 2010. Stepanov et al. concluded that TSNA levels in tobacco filler of U.S. cigarettes had remained unchanged over time despite the tobacco manufacturers expressed intention to use low-TSNA flue-cured tobacco varieties in their commercial products. The results of the current study are consistent with the conclusion of Stepanov et al. Variation in cultivation practices, curing methods, nicotine and minor alkaloid content, as well as tobacco blend composition can all influence TSNA amounts in tobacco filler and may explain the wide variations seen in this study. In addition, U.S. cigarettes comprise tobacco from multiple crop-years, geographical regions, and curing batches, which naturally have different nitrosamine levels in the tobacco blends. ${ }^{46}$ Most of the cigarettes in this study contain an American blend tobacco filler. They have total TSNA amounts between $2.5-5.5 \mu \mathrm{g} / \mathrm{g}$, tobacco. One outlier (American Spirit Blue, HP) has much lower TSNA amounts, because it is composed of all flue-cured tobacco.

Agronomic and postharvest processing of tobacco leaves can affect the TSNA content in tobacco filler of the cigarettes tested; in addition, the variation of smoke yields seen with the standard ISO machine-smoking regimen indicates that filter ventilation is a major determinant in levels of mainstream smoke TSNA levels obtained by that method. The role of filter ventilation on machine-smoke TSNA yield has been previously reported. ${ }^{27}$ In this study, the reported TSNA deliveries inversely correlate with increasing percent filter ventilation for the cigarette products that have been smoked using the ISO regimen . Carlton White100s, HP exhibited the lowest total TSNA amounts in smoke and has nearly the highest percent filter ventilation (62\%) among the cigarettes examined. In contrast, Winston Red 100s, HP exhibited the highest total TSNA amounts in smoke and ranks among the brands with the lowest percent filter ventilation (19\%). Dilution of TSNA amounts in smoke particulates by air pulled through filter ventilation holes, during ISO machine-smoking regimen, results in substantial reductions in machine-smoke yields of Carlton White 100s, HP compared to cigarette brands with much lower percentage ventilation. Thus, data generated using smoking regimens with unblocked filter vents give the illusion that the consumer will experience a lower exposure to TSNAs while data based on CI machinesmoking regimen indicates that common use behaviors likeblocking filter vents and taking larger puffs will result in larger exposures.

In contrast to TSNA results for the ISO machine-smoking regimen, the smoke yields by CI machine-smoking regimen indicate that no single product attribute has a dominant influence on the mainstream smoke TSNA yields as determined through a multivariate analysis. The most recognizable impact of the CI regimen was an average 2.5-fold increase in absolute TSNA smoke yields compared to ISO smoking regimen. In addition, as indicated in Tables 2 and 3, with exception of American Spirit Blue, HP and Winston Red 100s, HP, the rankorder of all cigarette brands was inconsistent with the relative difference in filter ventilation levels as observed for the ISO machine-smoking regimen. For example, Carlton White 100s HP and Doral Gold, HP TSNA amounts ranks lowest and $22^{\text {nd }}$ lowest, respectively when measured using the ISO machine-smoking regimen(Table 2). However, they are $11^{\text {th }}$ and $7^{\text {th }}$ lowest, respectively when measured using the CI machine-smoking regimen, (Table 3). For all of the cigarettes examined, higher smoke yields and differences in rank order for the two smoking regimens are largely attributable to the change in puff volume, frequency, and 
blocked ventilation. The effect of puff volume and puff frequency on smoke yields of TSNAs has been documented. ${ }^{47}$ The results reported herein demonstrate that testing smoke deliveries of various US cigarette brands can reveal the highest range of TSNA yields of American cigarettes that cannot be readily ascertained from the filler TSNA content or standard smoking conditions.

As the smoking parameters such as puff volume change or occlusion of filter ventilation holes occurs during intense smoking with ventilation blockage, conditions in the burning cigarette and reactivity of smoke changes ${ }^{48}$, which could alter both the fraction of TSNAs transferring directly from tobacco filler to smoke and particularly quantities produced by nitrosation of nicotine and minor alkaloids by nitrogen oxides during combustion. For these reasons, the transfer efficiency for all four TSNAs in each cigarette product was estimated as the ratio of smoke yields and tobacco filler TSNA amounts without regard for the origin of the TSNA in smoke. This analysis shows extensive variation of the estimated transfer efficiency of individual TSNAs within each product and among the cigarette brands tested (Supporting Information Figure S-1). When smoking the cigarettes under either ISO or CI machine-smoking regimens, NAB and NNK appear to transfer more efficiently from tobacco filler to smoke, compared to NNN and NAT (Figure 2) for all products tested. The average transfer efficiency for NNN (7\%) and NAT (9\%) by the ISO machine-smoking regimen are comparable to previous reports for cigarettes treated with [pyridine-D4]-NNN prior to smoking by the same smoking regimen. ${ }^{25,27}$ In contrast, the average results for NNK (24\%) and NAB (16.4\%) are substantially greater than transfer values determined with [pyridineD4]-NNK under ISO smoking regimen. ${ }^{25}$ No published study of transfer for US commercial cigarette products by the CI machine-smoking regimen was found for comparison. A key limitation of these values is that estimates of the transfer efficiency values were obtained from the ratio of smoke TSNA yields with respect to tobacco filler TSNA amounts for each cigarette, not by the an external approach which uses isotopically labeled TSNAs added to unburned tobacco before combustion. ${ }^{25,36}$ The extent to which pyrosynthesis affects TSNA yields was not determined here, but likely contributes to the overall apparent transfer efficiencies that are observed.

The reasons for differences in transfer efficiency of NNK and NAB with respect to NNN and NAT from filler to smoke for all the cigarettes examined are unclear. As stated previously, the transfer efficiency is highest for NNK and NAB compared to both NNN and NAT in the entire set of cigarette brands examined. Indeed, all of the cigarettes contain a cellulose acetate filter, which indiscriminately sequester tobacco constituents that are dispersed in smoke particulates. ${ }^{49}$ Thus, all four TSNAs in smoke particulates arriving at the filter should experience the same rate of filtration by the filter and theoretically should have similar transfer efficiency from tobacco filler to mainstream smoke as nicotine. However, unique chemical properties of the TSNA molecules, e.g., vapor pressure, thermal lability, and polarity likely impact how the TSNAs partition between filler and smoke. Furthermore, the extent of thermal decomposition during smoking is unknown. Fisher et al. claims that TSNAs in smoke originate exclusively by direct transfer from tobacco filler in the particulate phase of mainstream smoke and is unaffected by pyrosynthesis during tobacco pyrolysis. ${ }^{27}$ In the present study, all of the cigarettes examined exhibited remarkable differences in percentage transfer to smoke (Supplemental Figure 1). Several studies of commercial 
cigarette products that were spiked with isotopically enriched TSNA precursors (e.g., [pyrrolidine-2- ${ }^{14} \mathrm{C}$ ]-nicotine) suggest that TSNAs in smoke could originate from a combination of direct transfer from tobacco and pyrosynthesis during tobacco pyrolysis. ${ }^{38}$ Adams et al. ${ }^{38}$ report that nearly $60-70 \%$ of NNK in smoke originate from pyrosynthesis during tobacco combustion. In addition, Moldoveanu et al. ${ }^{50}$ report that approximately 5 $10 \%$ of NNK and $5-25 \%$ of NNN in mainstream smoke originated from pyrosynthesis during the smoking process. These previous studies and the results of this study suggest that NNK and NAB form more readily by pyrosynthesis during combustion of cigarettes with higher amounts of Burley tobacco than do NNN and NAT without consideration of thermal degradation effects. Additional information on the extent of thermal degradation of TSNAs during combustion would be useful to determine whether smoke yields of NNK and NAB are a result of different mechanisms for release from tobacco filler or pyrosynthesis during pyrolysis. NNN is considered an esophageal carcinogen and was measured at higher levels than NNK which is a more potent carcinogen and causes lung tumors ${ }^{7}$ Thus, limiting the percentage of NNK and NNN transferring from tobacco to smoke may be another important consideration for reducing exposure to strong known human carcinogens in US domestic cigarette products.

As stated, NNN and NNK are designated HPHCs and are frequently the only TSNAs reported in tobacco and tobacco smoke. ${ }^{23,26,31,36} \mathrm{In}$ addition, tobacco manufacturers now test and report only these two TSNAs in their cigarette products. However, NNN and NNK by themselves do not indicate the total TSNA exposure in smoke. NAB and NAT add to TSNA inhalation exposure. A part of this study was to investigate whether any of the commonly measured TSNAs can predict total TSNA amounts in tobacco filler and smoke of American blend cigarette products. For this purpose, the total TSNA amounts were determined by summing the measured quantities of all four TSNAs in each product. Therefore, the correlation of each TSNA with the total amounts is largely dependent on underlying associations between the individual TSNAs themselves (Supporting information Tables S-2, S-3 and S-4) as well as the relative contribution of each TSNA to the total amounts. For these reasons a high correlation coefficient by itself is not indicative of goodness of linear fit ${ }^{56}$ or appropriateness for predicting total TSNA amounts. Therefore, to test this hypothesis we randomly selected 30 cigarettes as exploratory cigarettes having total TSNA amounts spanning the range of amounts in all commercial cigarettes tested. First, we generated best-fit linear regression statistics (slope, intercept, and $\mathrm{R}^{2}$,) for each TSNA and total TSNA amounts using the exploratory brands. The products remaining after randomized selection of the exploratory set of cigarettes served as validation cigarette products. We then determined the mean percentage difference (\%DIFF) between the total TSNA quantities, based on sum of measured individual TSNAs, and predicted values for the validation brands.

The results of this analysis revealed that quantities of all four TSNAs might predict total TSNA amounts in both filler and smoke with low \%DIFF for the set of validation cigarette products (Table 4). Predicted total TSNA amounts in tobacco filler and in smoke, calculated from the linear regression statistics, are comparable to total TSNA quantities derived from the sum of measured quantities of all four TSNAs. In tobacco filler and mainstream smoke of the validation cigarettes, NNN, NAT, and NAB quantities have moderate to strong correlations with total TSNA amounts. The coefficients of determination $\left(\mathrm{R}^{2}\right)$ range from 
0.61 to 0.89 in tobacco filler and are all greater than 0.92 for the association in smoke. Additionally, NNN, NAT, and NAB exhibit low \%DIFF and comparable 95-percent confidence limits about the \%DIFF. These results suggest that NNN, NAT, and NAB by themselves may reliably predict total TSNA amounts in tobacco filler of American blend cigarette products if the relative amounts of each TSNA in the tobacco filler are preserved. Similarly, NNN, NAT, and NAB by themselves may reliably predict total TSNA amounts in smoke by ISO and CI machine-smoking regimens if the design characteristics of the cigarette are within the range for the products used to establish the linear regression function. In contrast, the wider 95-percent confidence limits around the \%DIFF based on NNK quantities suggest that measured amounts of NNK in tobacco filler and smoke yields may be a less reliable predictor of total TSNA amounts in both tobacco matrices.

\section{CONCLUSION}

US commercial cigarette products exhibit wide variation in harmful TSNA amounts in the tobacco filler and in mainstream smoke. Much of the variation in tobacco filler TSNA amounts could be attributable to differences in cultivation and curing practices. Changes in tobacco cultivation and manufacturing practices may lead to reductions in TSNA amounts in tobacco filler. Such an approach may be the most straightforward method for reducing the overall smoke yields of TSNAs. In addition, smoke yields of TSNAs are strongly associated with brand-to-brand variations of physical attributes of the cigarette products. Consequently, low smoke yields from ISO machine-smoking regimen do not always translate to low yields with more intensive machine-smoking regimens such as CI. NNN, NAT, and NAB amounts in tobacco and smoke may be useful to predict the total TSNA amounts in the Americanblend tobacco filler and from cigarette smoke, in cigarettes that have the same tobacco blend and similar design attributes.

\section{Supplementary Material}

Refer to Web version on PubMed Central for supplementary material.

\section{ACKNOWLEDGEMENTS}

The authors would like to thank Antonio Paredes for performing the statistical analysis of the TSNA data.

\section{ABBREVIATIONS}

TSNA

HPHCs

FD\&C

FDA

ISO

CI
Tobacco-specific nitrosamine

Harmful and potentially harmful constituents

Federal Food Drug \& Cosmetic Control Act

Food and Drug Administration

International Organization of Standards machine-smoking regimen

Canadian Intense machine-smoking regimen

Chem Res Toxicol. Author manuscript; available in PMC 2018 February 20. 


$\begin{array}{ll}\text { NAB } & \text { N-nitrosoanabasine } \\ \text { NNK } & \text { 4-(methylnitrosamino)-1-(3-pyridyl)-1-butanone } \\ \text { NAT } & \text { N-nitrosoanatabine } \\ \text { and NNN } & \text { N-nitrosonornicotine } \\ \text { Total TSNA } & \text { the sum of all four TSNAs (NAB, NNK, NAT, and NNN) } \\ \text { \%DIFF } & \text { Mean relative prediction error } \\ \text { SD } & \text { Standard deviation of the average } \\ \text { SE } & \text { Standard error } \\ \text { LC } & \text { Liquid chromatography } \\ \text { MS } & \text { Mass spectrometry } \\ \text { HP } & \text { Hard pack } \\ \text { SP } & \text { Soft pack }\end{array}$

\section{REFERENCES}

(1). U. S. Department of Health and Human Services. The health consequences of smoking-50 years of progress. A report of the surgeon general. U.S. Department of Health and Human Services, Centers for Disease Control and Prevention, National Center for Chronic Disease Prevention and Health Promotion, Office on Smoking Health; Atlanta: 2014. http://www.surgeongeneral.gov/ library/reports/50-years-of-progress/full-report.pdf. Accessed June, 2016

(2). Warren GW, Alberg AJ, Kraft AS, Cummings KM. The 2014 Surgeon General's report: "The health consequences of smoking--50 years of progress": a paradigm shift in cancer care. Cancer. 2014; 120:1914-1916. [PubMed: 24687615]

(3). U.S. Department of Health and Human Services. The health consequences of smoking: a report of the Surgeon General. Vol. 62. US Department of Health and Human Services, Centers for Disease Control and Prevention, National Center for Chronic Disease Prevention and Health Promotion, Office on Smoking and Health; Atlanta, GA: 2004. http://www.cdc.gov/tobacco/ data_statistics/sgr/2004/, Accessed June, 2016

(4). Hecht SS. Tobacco smoke carcinogens and lung cancer. J Natl Cancer Inst. 1999; 91:1194-1210. [PubMed: 10413421]

(5). Hammond D, O'Connor RJ. Constituents in tobacco and smoke emissions from Canadian cigarettes. Tob Control. 2008; 17(Suppl 1):i24-i31. [PubMed: 18768456]

(6). Hecht SS, Chen CB, Hirota N, Ornaf RM, Tso TC, Hoffmann D. Tobacco-specific nitrosamines: formation from nicotine in vitro and during tobacco curing and carcinogenicity in strain A mice. J Natl. Cancer Inst. 1978; 60:819-824. [PubMed: 633391]

(7). Hecht SS, Chen CB, Ohmori T, Hoffmann D. Comparative carcinogenicity in F344 rats of the tobacco-specific nitrosamines, N'-nitrosonornicotine and 4-(N-methyl-N-nitrosamino)-1-(3pyridyl)-1-butanone. Cancer Res. 1980; 40:298-302. [PubMed: 7356512]

(8). Hecht SS, Adams JD, Numoto S, Hoffmann D. Induction of respiratory tract tumors in Syrian golden hamsters by a single dose of 4-(methylnitrosamino)-1-(3-pyridyl)-1-butanone (NNK) and the effect of smoke inhalation. Carcinogenesis. 1983; 4:1287-1290. [PubMed: 6616756]

(9). Hecht SS, Rivenson A, Braley J, DiBello J, Adams JD, Hoffmann D. Induction of oral cavity tumors in F344 rats by tobacco-specific nitrosamines and snuff. Cancer Res. 1986; 46:41624166. [PubMed: 3731083] 
(10). Hoffmann D, Raineri R, Hecht SS, Maronpot R, Wynder EL. A study of tobacco carcinogenesis. XIV. Effects of N'-nitrosonornicotine and N'-nitrosonanabasine in rats. J Natl. Cancer Inst. 1975; 55:977-981. [PubMed: 1237631]

(11). Hoffmann D, Rivenson A, Amin S, Hecht SS. Dose-response study of the carcinogenicity of tobacco-specific N-nitrosamines in F344 rats. J Cancer Res Clin Oncol. 1984; 108:81-86. [PubMed: 6746721]

(12). Rivenson A, Hoffmann D, Prokopczyk B, Amin S, Hecht SS. Induction of lung and exocrine pancreas tumors in F344 rats by tobacco-specific and Areca-derived N-nitrosamines. Cancer Res. 1988; 48:6912-6917. [PubMed: 3180100]

(13). Hoffmann D, Hoffmann I. The changing cigarette, 1950-1995. J Toxicol. Environ. Health. 1997; 50:307-364. [PubMed: 9120872]

(14). Hecht SS. Biochemistry, biology, and carcinogenicity of tobacco-specific N-nitrosamines. Chemical research in toxicology. 1998; 11:559-603. [PubMed: 9625726]

(15). Djordjevic MV, Gay SL, Bush LP, Chaplin JF. Tobacco-specific nitrosamine accumulation and distribution in flue-cured tobacco alkaloid isolines. Journal of Agricultural and Food Chemistry. 1989; 37:752-756.

(16). de Roton, Wiernik, A., Wahlberg, I., Vidal, B. Factors influencing the formation of tobaccospecific nitrosamines in French air-cured tobaccos in trials and at the farm level. Beitrage zur Tabkforschung International. 2005; 21:305-319.

(17). Bhide S, Nair J, Maru G, Nair U, Kameshwar Rao B, Chakraborty M, Brunnemann K. Tobaccospecific N-nitrosamines [TSNA] in green mature and processed tobacco leaves from India. Beiträge zur Tabakforschung/Contributions to Tobacco Research. 1987; 14:29-32.

(18). Hilfrich J, Hecht SS, Hoffmann D. A study of tobacco carcinogenesis. XV. Effects of N'nitrosonornicotine and N'-nitrosoanabasine in Syrian golden hamsters. Cancer Lett. 1977; 2:169_ 175. [PubMed: 837363]

(19). International Agency for Research of Cancer. Monographs on the evaluation of carcinogenic risk of carcinogenic chemicals to humans. IARC Press; Lyon, France, Lyon, France: 1986. p. 55-60.

(20). Food and Drug Administration. Harmful and potentially harmful constituents in tobacco products and tobacco smoke; established list. Federal Registry. 2012; 77:20034-20037.

(21). Brunnemann KD, Hecht SS, Hoffmann D. N-nitrosamines: environmental occurrence, in vivo formation and metabolism. J Toxicol Clin. Toxicol. 1982; 19:661-688. [PubMed: 6761448]

(22). Burton H, Dye N, Bush L. Relationship between tobacco-specific nitrosamines and nitrite from different air-cured tobacco varieties. 1994:2007-2011.

(23). Ashley DL, Beeson MD, Johnson DR, McCraw JM, Richter P, Pirkle JL, Pechacek TF, Song S, Watson CH. Tobacco-specific nitrosamines in tobacco from U.S. brand and non-U.S. brand cigarettes. Nicotine Tob. Res. 2003; 5:323-331. [PubMed: 12791527]

(24). Fischer S, Spiegelhalder B, Preussmann R. Tobacco-specific nitrosamines in European and USA cigarettes. Arch. Geschwulstforsch. 1990; 60:169-177. [PubMed: 2369279]

(25). Stepanov I, Knezevich A, Zhang L, Watson CH, Hatsukami DK, Hecht SS. Carcinogenic tobacco-specific N-nitrosamines in US cigarettes: three decades of remarkable neglect by the tobacco industry. Tob Control. 2012; 21:44-48. [PubMed: 21602537]

(26). Wu W, Zhang L, Jain RB, Ashley DL, Watson CH. Determination of carcinogenic tobaccospecific nitrosamines in mainstream smoke from U.S.-brand and non-U.S.-brand cigarettes from 14 countries. Nicotine Tob Res. 2005; 7:443-451. [PubMed: 16085512]

(27). Fischer S, Castonguay A, Kaiserman M, Spiegelhalder B, Preussmann R. Tobacco-specific nitrosamines in Canadian cigarettes. J Cancer Res Clin. Oncol. 1990; 116:563-568. [PubMed: 2254375]

(28). Adams JD, Lee SJ, Hoffmann D. Carcinogenic agents in cigarette smoke and the influence of nitrate on their formation. Carcinogenesis. 1984; 5:221-223. [PubMed: 6697439]

(29). Chen PX, Moldoveanu SC. Mainstream smoke chemical analyses for 2R4F Kentucky reference cigarette. Beitr+ñge zur Tabakforshung International/Contributions to Tobacco Research. 2003; 20 
(30). Counts ME, Hsu FS, Laffoon SW, Dwyer RW, Cox RH. Mainstream smoke constituent yields and predicting relationships from a worldwide market sample of cigarette brands: ISO smoking conditions. Regul. Toxicol Pharmacol. 2004; 39:111-134. [PubMed: 15041144]

(31). Ding YS, Zhang L, Jain RB, Jain N, Wang RY, Ashley DL, Watson CH. Levels of tobaccospecific nitrosamines and polycyclic aromatic hydrocarbons in mainstream smoke from different tobacco varieties. Cancer Epidemiol. Biomarkers Prev. 2008; 17:3366-3371. [PubMed: 19064552]

(32). Fischer S, Spiegelhalder B, Preussmann R. Tobacco-specific nitrosamines in mainstream smoke of West German cigarettes--tar alone is not a sufficient index for the carcinogenic potential of cigarette smoke. Carcinogenesis. 1989; 10:169-173. [PubMed: 2910520]

(33). World Health Organization. Guiding principles for the development of tobacco product research and testing capacity and proposed protocols for the initiation of tobacco product testing. Tobacco Control. 2005

(34). Burns DM, Dybing E, Gray N, Hecht S, Anderson C, Sanner T, O’Connor R, Djordjevic M, Dresler C, Hainaut P. Mandated lowering of toxicants in cigarette smoke: a description of the World Health Organization TobReg proposal. Tobacco Control. 2008; 17:132-141. [PubMed: 18375736]

(35). Fischer S, Spiegelhalder B, Preussmann R. Preformed tobacco-specific nitrosamines in tobacco-role of nitrate and influence of tobacco type. Carcinogenesis. 1989; 10:1511-1517. [PubMed: 2752525]

(36). Fischer S, Spiegelhalder B, Eisenbarth J, Preussmann R. Investigations on the origin of tobaccospecific nitrosamines in mainstream smoke of cigarettes. Carcinogenesis. 1990; 11:723-730. [PubMed: 2335004]

(37). Fischer S, Spiegelhalder B, Preussmann R. Tobacco-specific nitrosamines in commercial cigarettes: possibilities for reducing exposure. IARC Sci. Publ. 1991:489-492. [PubMed: 1855903]

(38). Adams JD, Lee SJ, Vinchkoski N, Castonguay A, Hoffmann D. On the formation of the tobaccospecific carcinogen 4-(methylnitrosamino)-1-(3-pyridyl)-1-butanone during smoking. Cancer Lett. 1983; 17:339-346. [PubMed: 6831390]

(39). Hoffmann D, Dong M, Hecht SS. Origin in tobacco smoke of N'-nitrosonornicotine, a tobaccospecific carcinogen. J Natl. Cancer Inst. 1977; 58:1841-1844. [PubMed: 864762]

(40). International Organization of Standards. Standard 3308: Routine analytical cigarette-smoking machine-definitions and standard conditions. International Organization for Standards; Geneva: 2012.

(41). World Health Organization. Standard operating procedure for intense smoking of cigarettes, Tobacco Laboratory Network (TobLabNet) Official Method, Standard Operating Procedure. 2012:1.

(42). Wu W, Ashley DL, Watson CH. Simultaneous determination of five tobacco-specific nitrosamines in mainstream cigarette smoke by isotope dilution liquid chromatography/ electrospray ionization tandem mass spectrometry. Anal. Chem. 2003; 75:4827-4832. [PubMed: 14674460]

(43). Roemer E, Schorp MK, Piade JJ, Seeman JI, Leyden DE, Haussmann HJ. Scientific assessment of the use of sugars as cigarette tobacco ingredients: a review of published and other publicly available studies. Crit. Rev Toxicol. 2012; 42:244-278. [PubMed: 22263649]

(44). Alberg AJ, Shopland DR, Cummings KM. The 2014 Surgeon General's report: commemorating the 50th Anniversary of the 1964 Report of the Advisory Committee to the US Surgeon General and updating the evidence on the health consequences of cigarette smoking. Am. J. Epidemiol. 2014; 179:403-412. [PubMed: 24436362]

(45). Gray N, Boyle P. The case of the disappearing nitrosamines: a potentially global phenomenon. Tob Control. 2004; 13:13-16. [PubMed: 14985588]

(46). Zuber J, d'Andres S, Boudoux R, Renaud JM. TSNA Levels in the Mainstream Smoke of Simplified Blend Prototypes. Beitr+ñge zur Tabakforschung/Contributions to Tobacco Research. 20:331-340. 
(47). Fischer S, Spiegelhalder B, Preussmann R. Influence of smoking parameters on the delivery of tobacco-specific nitrosamines in cigarette smoke--a contribution to relative risk evaluation. Carcinogenesis. 1989; 10:1059-1066. [PubMed: 2720900]

(48). Liu C, G McAdam K, A Perfetti T. Some recent topics in cigarette smoke science. Mini-Reviews in Organic Chemistry. 2011; 8:349-359.

(49). O'Connor RJ, Hurley PJ. Existing technologies to reduce specific toxicant emissions in cigarette smoke. Tob Control. 2008; 17(Suppl 1):i39-i48. [PubMed: 18768458]

(50). Moldoveanu SC, Borgerding M. Formation of tobacco specific nitrosamines in mainstream cigarette smoke; part 1, FTC smoking. Beitr+ñge zur Tabakforschung/Contributions to Tobacco Research. 2008; 23:19-31. 


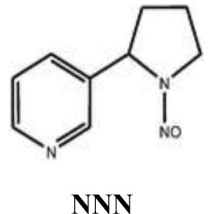

NNN

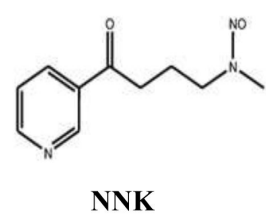

NNK<smiles>ON1CCCCC1c1cccnc1</smiles>

NAB

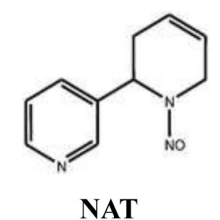

Figure 1.

Chemical structures of four commonly measured TSNAs 


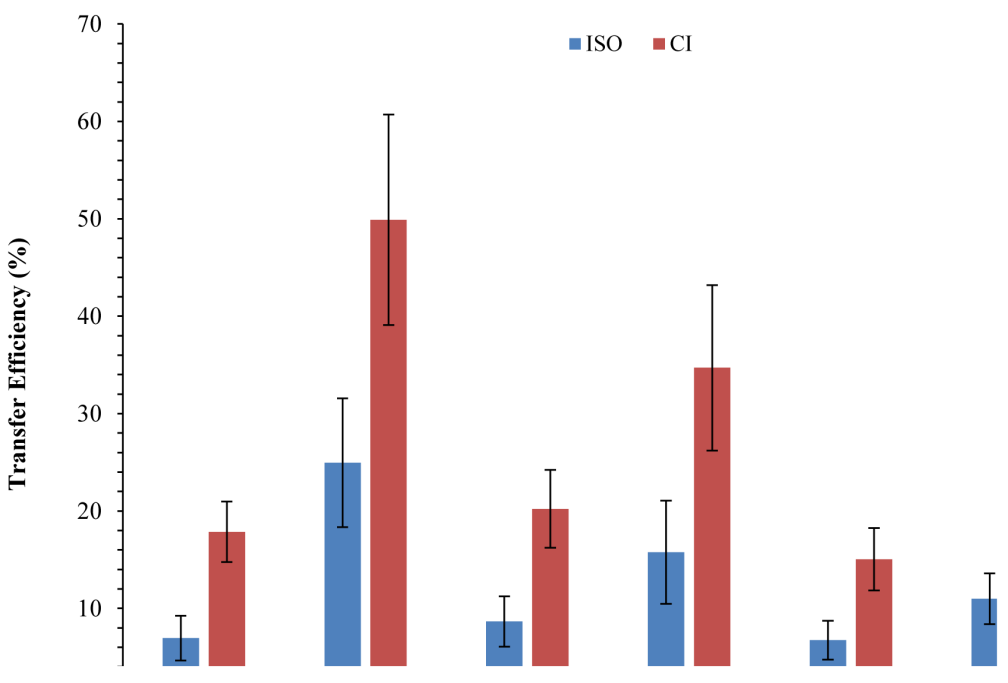

Figure 2.

Average transfer efficiency (\%) of TSNA from tobacco filler to mainstream smoke by ISO and CI machine smoking regimens. Transfer Efficiency $(\%)=100 \times[$ Smoke TSNA (ng/cig)/ Filler TSNA (ng/cig)] 

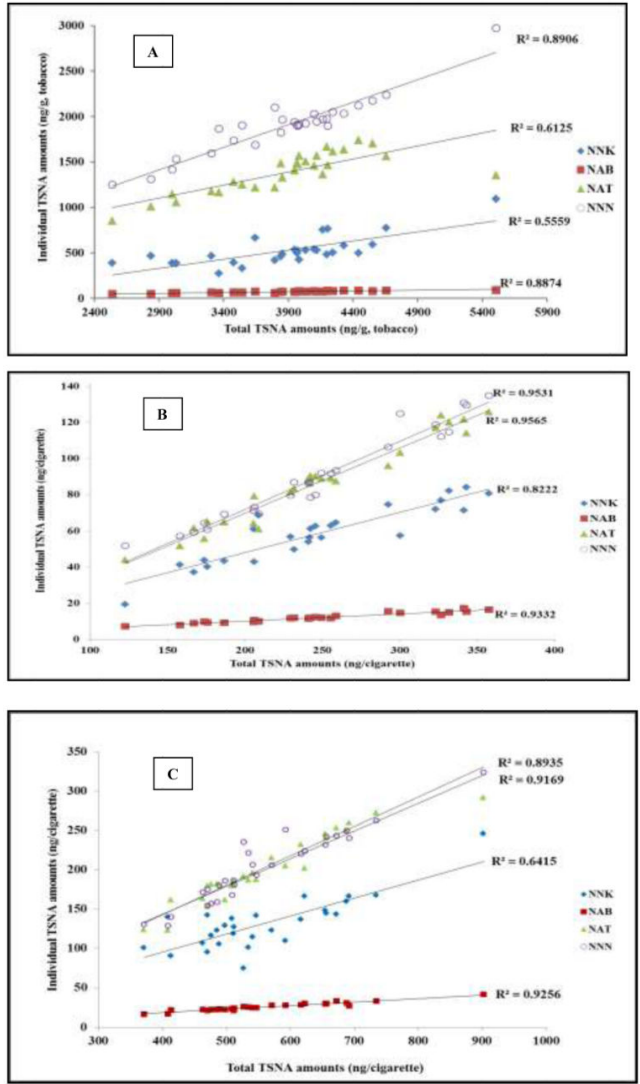

Figure 3.

Linear association of individual and total TSNA amounts in commercial cigarettes; (A) tobacco filler, (B) ISO and (C) CI mainstream smoke 


\section{Table 1}

Levels of TSNAs in tobacco filler of US domestic cigarette products. The cigarettes are rank-ordered from highest to lowest total TSNA levels.

Tobacco-Specific Nitrosamines (ng/g, tobacco) ${ }^{a}$,

\begin{tabular}{|c|c|c|c|c|c|}
\hline Cigarette Products & $\mathrm{NAB} \pm \mathrm{SD}$ & $\mathrm{NNK} \pm \mathrm{SD}$ & $\mathrm{NAT} \pm \mathrm{SD}$ & $\mathbf{N N N} \pm \mathbf{S D}$ & Total $\pm \mathrm{SE}$ \\
\hline Doral Gold, HP & $91.5 \pm 2.3$ & $1092.9 \pm 17.0$ & $1351.4 \pm 31.3$ & $2970 \pm 175.5$ & $5505.8 \pm 15.0$ \\
\hline Merit Gold, SP & $88.1 \pm 3.8$ & $474.6 \pm 27.7$ & $1875.7 \pm 35.5$ & $2431.4 \pm 237.8$ & $4869.8 \pm 17.5$ \\
\hline Marlboro Red Label, HP & $88.3 \pm 1.9$ & $607.3 \pm 35.1$ & $1775.7 \pm 40.8$ & $2268.6 \pm 52.2$ & $4739.9 \pm 11.4$ \\
\hline Winston Gold 100s, HP & $85.5 \pm 2.7$ & $773.3 \pm 92.4$ & $1562.9 \pm 41.1$ & $2237.1 \pm 112.8$ & $4658.8 \pm 15.9$ \\
\hline Marlboro Red 100s, HP & $82.5 \pm 1.4$ & $593.7 \pm 13.6$ & $1705.7 \pm 32$ & $2171.4 \pm 52.7$ & $4553.3 \pm 10$ \\
\hline Winston Red 100s, HP & $81.2 \pm 3.3$ & $775.7 \pm 29.2$ & $1544.3 \pm 46.2$ & $2124.3 \pm 75.7$ & $4525.5 \pm 12.4$ \\
\hline NOW Gold 100s, SP & $85.9 \pm 4.6$ & $571.6 \pm 34.7$ & $1687.1 \pm 30.9$ & $2158.6 \pm 72$ & $4503.2 \pm 11.9$ \\
\hline Marlboro Silver HP & $82.9 \pm 1.8$ & $498.9 \pm 15.6$ & $1740 \pm 19.5$ & $2121.4 \pm 44.9$ & $4443.2 \pm 9.0$ \\
\hline Marlboro Red 100s, SP & $83.3 \pm 4.2$ & $583 \pm 91.4$ & $1632.9 \pm 44.3$ & $2030 \pm 66.4$ & $4329.1 \pm 14.4$ \\
\hline Basic Green 100s, HP & $82.5 \pm 2.2$ & $617 \pm 14.5$ & $1502.9 \pm 44.5$ & $2091.4 \pm 54.4$ & $4293.8 \pm 10.8$ \\
\hline Marlboro Gold 100s, HP & $79.1 \pm 1.7$ & $502 \pm 98$ & $1614.3 \pm 30$ & $2050 \pm 37.8$ & $4245.4 \pm 12.9$ \\
\hline Salem Gold, HP & $83.5 \pm 3.3$ & $763.1 \pm 26.6$ & $1461.4 \pm 50.6$ & $1895.7 \pm 86.5$ & $4203.8 \pm 12.9$ \\
\hline Marlboro Green, HP & $77.7 \pm 1.7$ & $480.3 \pm 15.8$ & $1667.1 \pm 18.1$ & $1974.3 \pm 77.3$ & $4199.4 \pm 10.6$ \\
\hline VA Slim Gold Slims, HP & $78 \pm 2.5$ & $539.6 \pm 34.5$ & $1474.3 \pm 40.8$ & $2072.9 \pm 113$ & $4164.7 \pm 13.8$ \\
\hline Carlton White 100s, HP & $85.5 \pm 4.3$ & $585.9 \pm 39.5$ & $1527.1 \pm 20.6$ & $1967.1 \pm 93.8$ & $4165.6 \pm 12.6$ \\
\hline B\&H Green 100s, HP & $79 \pm 3.4$ & $466 \pm 20.2$ & $1580 \pm 10.7$ & $2060 \pm 36$ & $4185 \pm 8.4$ \\
\hline Kool Green, SP & $75.2 \pm 4.8$ & $755.4 \pm 52.7$ & $1364.3 \pm 63.7$ & $1970 \pm 115.3$ & $4164.9 \pm 15.4$ \\
\hline Basic Gold 100s, SP & $81.5 \pm 2.3$ & $557.1 \pm 22$ & $1408.6 \pm 36.1$ & $2072.9 \pm 79.2$ & $4120 \pm 11.8$ \\
\hline Marlboro Red, HP & $75.8 \pm 3.3$ & $527.6 \pm 48$ & $1570 \pm 32.6$ & $1945.7 \pm 62$ & $4119.1 \pm 12.1$ \\
\hline Basic Gold 100s, HP & $80.6 \pm 4.4$ & $538.1 \pm 72.4$ & $1455.7 \pm 34.0$ & $2024.31 \pm 55.2$ & $4098.7 \pm 12.9$ \\
\hline Marlboro Silver 100s, HP & $76.3 \pm 2.8$ & $466.1 \pm 27.9$ & $1571.4 \pm 78.3$ & $1958.6 \pm 85.1$ & $4072.5 \pm 13.9$ \\
\hline Salem Gold 100s, HP & $77.5 \pm 3.8$ & $528.1 \pm 65.7$ & $1505.7 \pm 40.2$ & $1921.4 \pm 58.8$ & $4032.8 \pm 13$ \\
\hline Winston White 100s, HP & $71.3 \pm 2.7$ & $729.9 \pm 30$ & $1318.6 \pm 44.5$ & $1912.9 \pm 57.4$ & $4032.6 \pm 11.6$ \\
\hline Marlboro Gold, HP & $79.1 \pm 2.4$ & $426.9 \pm 60$ & $1565.7 \pm 54.4$ & $1911.4 \pm 109.2$ & $3983.1 \pm 15.0$ \\
\hline Marlboro Gold, SP & $77 \pm 2.9$ & $523.3 \pm 39.2$ & $1474.3 \pm 82.4$ & $1898.6 \pm 137.8$ & $3973.1 \pm 16.2$ \\
\hline Marlboro Red, SP & $73.5 \pm 1.9$ & $497.6 \pm 54.1$ & $1487.1 \pm 50.9$ & $1908.6 \pm 64.3$ & $3966.8 \pm 13.1$ \\
\hline Salem Green, HP & $71.3 \pm 3.5$ & $534.3 \pm 25.7$ & $1405.7 \pm 47.6$ & $1938.6 \pm 57.3$ & $3949.8 \pm 1156$ \\
\hline Parliament Blue, HP & $74 \pm 2.6$ & $438 \pm 15.1$ & $1511.4 \pm 41.8$ & $1918.6 \pm 69.6$ & $3942 \pm 11.4$ \\
\hline USA Gold 100s, SP & $64.9 \pm 2.5$ & $425.1 \pm 22.5$ & $1462.9 \pm 60$ & $1944.3 \pm 60.8$ & $3897.2 \pm 12.1$ \\
\hline Doral Silver 100s, HP & $78.3 \pm 3.2$ & $870.7 \pm 96.6$ & $1204.3 \pm 37.4$ & $1698.6 \pm 47.1$ & $3851.8 \pm 13.6$ \\
\hline Marlboro Gold 100s, SP & $74.4 \pm 2.2$ & $449.9 \pm 6.4$ & $1468.6 \pm 30$ & $1900 \pm 22.7$ & $3892.8 \pm 7.8$ \\
\hline Basic Blue 100s, HP & $73.3 \pm 4.5$ & $488.1 \pm 19$ & $1328.6 \pm 41.8$ & $1964.3 \pm 41.5$ & $3854.3 \pm 10.3$ \\
\hline Marlboro Menthol Gold, HP & $71.4 \pm 2.6$ & $462.9 \pm 16.9$ & $1484.3 \pm 22.2$ & $1824.3 \pm 50$ & $3842.8 \pm 9.6$ \\
\hline Newport Green 100s, HP & $61.9 \pm 2.9$ & $417.6 \pm 8.4$ & $1218.6 \pm 16.8$ & $2098.6 \pm 54.6$ & $3796.6 \pm 9.1$ \\
\hline Pall Mall Blue, HP & $69.7 \pm 6.0$ & $439.1 \pm 80.7$ & $1205.7 \pm 64$ & $2061.4 \pm 113$ & $3775.9 \pm 16.2$ \\
\hline Vantage Multicolor, SP & $74.4 \pm 2.8$ & $664.9 \pm 22.2$ & $1220 \pm 38.3$ & $1685.7 \pm 69.5$ & $3645 \pm 11.5$ \\
\hline
\end{tabular}


Tobacco-Specific Nitrosamines (ng/g, tobacco) ${ }^{a b}$

\begin{tabular}{llllll}
\cline { 2 - 5 } & \multicolumn{5}{c}{ Tobacco-Specific Nitrosamines (ng/g, tobacco) $\boldsymbol{a} \boldsymbol{b}$} \\
\hline Cigarette Products & NAB \pm SD & NNK \pm SD & NAT \pm SD & NNN \pm SD & Total \pm SE \\
\hline Winston Red, HP & $68.7 \pm 3.5$ & $561.6 \pm 10.6$ & $1270 \pm 119$ & $1742.9 \pm 81.6$ & $3643.1 \pm 14.7$ \\
Kent Golden, SP & $66 \pm 2.2$ & $366 \pm 16.3$ & $1252.9 \pm 32$ & $1961.4 \pm 72.7$ & $3646.3 \pm 11.1$ \\
Newport Green, HP & $64.9 \pm 2$ & $330.7 \pm 28.2$ & $1247.1 \pm 36.3$ & $1900 \pm 94.2$ & $3542.7 \pm 12.7$ \\
Newport Green SP & $60.5 \pm 3$ & $280.7 \pm 10.3$ & $1161.4 \pm 27.5$ & $2031.4 \pm 63$ & $3534.1 \pm 10.2$ \\
Salem Silver 100s, HP & $59.7 \pm 2.6$ & $491.1 \pm 47.1$ & $1230 \pm 25.8$ & $1677.1 \pm 35.9$ & $3458 \pm 10.6$ \\
B\&H Luxury 100s, SP & $67 \pm 1.8$ & $393.9 \pm 10.1$ & $1278.6 \pm 56.5$ & $1735.7 \pm 40.8$ & $3475.2 \pm 10.5$ \\
True Silver, SP & $59.7 \pm 5.4$ & $273.4 \pm 72.7$ & $1164.3 \pm 36.9$ & $1865.7 \pm 61.1$ & $3363.1 \pm 13.3$ \\
Capri Magenta SS, HP & $63.5 \pm 1.6$ & $489 \pm 42.1$ & $1230 \pm 24.5$ & $1530 \pm 32.2$ & $3312.5 \pm 10.0$ \\
Kool Green, HP & $65.3 \pm 1.5$ & $468.7 \pm 26$ & $1177.1 \pm 20.6$ & $1594.3 \pm 116.5$ & $3305.4 \pm 12.8$ \\
Misty Blue Slims, HP & $59 \pm 2.6$ & $386.1 \pm 14.7$ & $1055.7 \pm 21.5$ & $1530 \pm 25.2$ & $3030.8 \pm 8$ \\
Camel Blue, HP & $57.2 \pm 1.9$ & $385.7 \pm 17.6$ & $1142.9 \pm 18$ & $1415.7 \pm 45.0$ & $3001.5 \pm 9.1$ \\
Camel Filters, HP & $51.1 \pm 2.2$ & $464 \pm 55.7$ & $1008.7 \pm 19.5$ & $1312.9 \pm 30$ & $2836.7 \pm 10.4$ \\
Maverick Gold 100s, HP & $48.8 \pm 2$ & $388.9 \pm 7.3$ & $850.9 \pm 22.8$ & $1250 \pm 67.3$ & $2538.5 \pm 10$ \\
American Spirit Blue, HP ${ }^{b}$ & $20.5 \pm 0.9$ & $193.9 \pm 9.6$ & $320.4 \pm 5.7$ & $305.7 \pm 21.5$ & $840.5 \pm 6.1$ \\
3R4F & $20.3 \pm 1.0$ & $170 \pm 12$ & $421 \pm 18$ & $659 \pm 32$ & $1270.4 \pm$ \\
\hline & & & & & \\
\hline
\end{tabular}

NAB, N-nitrosoanabasine; NNK, 4-(methylnitrosamino)-1-(3-pyridyl)-1-butanone; NAT, N-nitrosoanatabine; and NNN, N-nitrosonornicotine; Total, (Sum of NNK, NAB, NAT, and NNN) (ng/cigarette); B\&H, Benson and Hedges; HP, Hard Pack; SP, Soft Pack; SD, Standard deviation;

${ }^{a} \mathrm{~N}=7$-replicate measurements; SE, Standard error;

$b_{100 \%}$ Flue-cured tobacco;

${ }^{c}$ American blend cigarette products 


\section{Table 2}

Levels of TSNAs in mainstream smoke of domestic cigarettes tested with the ISO machine-smoking regimen. The cigarettes are rank-ordered highest to lowest total TSNA yield.

Tobacco-Specific Nitrosamines (ng/cigarette) ${ }^{a}$ c

\begin{tabular}{|c|c|c|c|c|c|}
\hline Cigarette Products & $\mathrm{NAB} \pm \mathrm{SD}$ & $\mathrm{NNK} \pm \mathrm{SD}$ & $\mathrm{NAT} \pm \mathrm{SD}$ & $\mathbf{N N N} \pm \mathbf{S D}$ & Total \pm SE \\
\hline Winston Red 100s, HP & $22 \pm 1.3$ & $122.4 \pm 10.5$ & $145.1 \pm 10.9$ & $171.1 \pm 14.8$ & $460.8 \pm 6.1$ \\
\hline Marlboro Red 100s, HP & $16.4 \pm 1.0$ & $80.7 \pm 7.1$ & $125.7 \pm 11.8$ & $134.9 \pm 14.0$ & $357.6 \pm 5.8$ \\
\hline RJR Winston Red, HP & $17.7 \pm 2.4$ & $89.3 \pm 14.6$ & $111.3 \pm 7.9$ & $127 \pm 15.7$ & $345.4 \pm 6.4$ \\
\hline Marlboro Red, SP & $15.3 \pm 1.5$ & $84.4 \pm 11.1$ & $114.1 \pm 11.8$ & $129.6 \pm 21.8$ & $343.1 \pm 6.8$ \\
\hline Marlboro Red 100s, SP & $17.2 \pm 1.3$ & $71.5 \pm 5.2$ & $121.9 \pm 9.5$ & $131 \pm 9.1$ & $341.5 \pm 5.0$ \\
\hline Salem Green, HP & $14.8 \pm 2.2$ & $82.3 \pm 14.5$ & $120 \pm 20.9$ & $114.7 \pm 23.0$ & $331.9 \pm 7.8$ \\
\hline Marlboro Green, HP & $13.4 \pm 1.4$ & $76.9 \pm 10.7$ & $124 \pm 8.0$ & $112.3 \pm 12.8$ & $326.6 \pm 5.7$ \\
\hline Marlboro Red, HP & $15.3 \pm 1.1$ & $72.1 \pm 10.6$ & $117.1 \pm 11.1$ & $118.7 \pm 10.1$ & $323.2 \pm 5.7$ \\
\hline B\&H Green 100s, HP & $16.2 \pm 1.1$ & $72.3 \pm 6.3$ & $117.7 \pm 7.4$ & $109.6 \pm 6.9$ & $315.8 \pm 4.7$ \\
\hline Newport Green 100s, HP & $14.7 \pm 2.3$ & $57.4 \pm 8.2$ & $103.2 \pm 14.1$ & $125 \pm 12.1$ & $300.3 \pm 6.1$ \\
\hline Winston Gold, HP & $15.4 \pm 1.0$ & $74.7 \pm 6.7$ & $96 \pm 6.8$ & $106.5 \pm 8.4$ & $292.6 \pm 4.8$ \\
\hline Newport Green, SP & $14.1 \pm 1.5$ & $55.3 \pm 5.7$ & $98.1 \pm 11.6$ & $120.5 \pm 21.8$ & $288 \pm 6.4$ \\
\hline Basic Gold 100s, SP & $17.6 \pm 11.1$ & $70.9 \pm 16.8$ & $89.2 \pm 15.8$ & $104.8 \pm 17.7$ & $282.5 \pm 7.8$ \\
\hline USA Gold 100s, SP & $13.1 \pm 1.3$ & $57.1 \pm 6.9$ & $96.3 \pm 6.6$ & $108.4 \pm 11$ & $274.9 \pm 5.1$ \\
\hline Marlboro Red Label, HP & $13.3 \pm 0.9$ & $62.7 \pm 9.6$ & $96.2 \pm 8.2$ & $101 \pm 9.6$ & $273.2 \pm 5.3$ \\
\hline Basic Green 100s, HP & $12.7 \pm 1.8$ & $68.4 \pm 8.8$ & $86.1 \pm 11.4$ & $99.1 \pm 16.7$ & $266.3 \pm 6.2$ \\
\hline Newport Green, HP & $12.3 \pm 1.5$ & $50.6 \pm 7.1$ & $87.3 \pm 10.3$ & $111.2 \pm 14.3$ & $261.5 \pm 5.8$ \\
\hline Basic Gold 100s, HP & $12.9 \pm 1.5$ & $64.5 \pm 14.8$ & $87.6 \pm 12.7$ & $93.6 \pm 11.2$ & $258.6 \pm 6.3$ \\
\hline Marlboro Menthol Gold, HP & $11.6 \pm 1.6$ & $63 \pm 11.6$ & $89.1 \pm 9.8$ & $91.9 \pm 10.5$ & $255.5 \pm 5.8$ \\
\hline Marlboro Gold 100s, HP & $11.9 \pm 1.3$ & $56.2 \pm 8.5$ & $89 \pm 15.5$ & $92.1 \pm 15.2$ & $249.2 \pm 6.3$ \\
\hline Kool Green, SP & $12.2 \pm 1.5$ & $62.8 \pm 11.2$ & $90.4 \pm 8.4$ & $80 \pm 7.3$ & $245.4 \pm 5.3$ \\
\hline Kool Green, HP & $11.8 \pm 1.7$ & $61.2 \pm 9.9$ & $90.5 \pm 12.1$ & $78.6 \pm 13.1$ & $242.1 \pm 6.1$ \\
\hline Marlboro Gold, SP & $11.8 \pm 1.1$ & $56.2 \pm 5.0$ & $86.2 \pm 7.7$ & $87.4 \pm 9.6$ & $241.7 \pm 4.8$ \\
\hline Marlboro Gold, HP & $11.4 \pm 1.0$ & $54 \pm 5.5$ & $88.8 \pm 7.1$ & $86.6 \pm 10.2$ & $240.9 \pm 4.9$ \\
\hline Marlboro Gold 100s, SP & $12.2 \pm 0.8$ & $52.2 \pm 4.4$ & $86.1 \pm 3.9$ & $85.3 \pm 5.8$ & $236.2 \pm 3.9$ \\
\hline B\&H Luxury 100s, SP & $11.8 \pm 1.4$ & $49.8 \pm 6.5$ & $83.3 \pm 6.4$ & $86.8 \pm 7.5$ & $231.8 \pm 4.7$ \\
\hline Salem Gold, HP & $11.7 \pm 2.1$ & $56.6 \pm 13.3$ & $81.4 \pm 14.5$ & $79.7 \pm 13.1$ & $229.5 \pm 6.6$ \\
\hline Merit Gold, SP & $10.5 \pm 0.7$ & $54.2 \pm 15.4$ & $77.5 \pm 3.6$ & $79.4 \pm 6.7$ & $221.7 \pm 5.1$ \\
\hline Doral Gold, HP & $9.9 \pm 0.9$ & $68.5 \pm 6.1$ & $61 \pm 6.0$ & $69.6 \pm 8.4$ & $208.9 \pm 4.6$ \\
\hline Camel Filters, HP & $10.6 \pm 1.2$ & $42.9 \pm 3.6$ & $79.3 \pm 7.1$ & $73.1 \pm 2.1$ & $206 \pm 3.7$ \\
\hline Vantage Multicolor, SP & $9.5 \pm 1.1$ & $60.9 \pm 8.9$ & $64.2 \pm 6.7$ & $71.1 \pm 14.0$ & $205.6 \pm 5.5$ \\
\hline Parliament Blue, HP & $10.5 \pm 0.7$ & $45.8 \pm 8.3$ & $72.1 \pm 4.0$ & $72.1 \pm 3.2$ & $200.6 \pm 4.0$ \\
\hline Pall Mall Blue, HP & $9.1 \pm 1.0$ & $49.8 \pm 5.4$ & $59.6 \pm 6.8$ & $71.6 \pm 6.4$ & $190.1 \pm 4.4$ \\
\hline VA Slim Gold Slims, HP & $9.5 \pm 1.4$ & $43.5 \pm 4.7$ & $67.3 \pm 7.6$ & $67.7 \pm 5.7$ & $189 \pm 4.4$ \\
\hline Winston White 100 s, HP & $10.9 \pm 0.9$ & $51.1 \pm 3.2$ & $58.3 \pm 4.6$ & $66.7 \pm 5.9$ & $187 \pm 3.8$ \\
\hline Salem Gold 100s, HP & $9.2 \pm 1.5$ & $43.3 \pm 5.5$ & $64.9 \pm 5.4$ & $69.2 \pm 8.7$ & $186.6 \pm 4.6$ \\
\hline
\end{tabular}


Tobacco-Specific Nitrosamines (ng/cigarette) ${ }^{a}$,

\begin{tabular}{llllll}
\cline { 2 - 5 } & \multicolumn{5}{l}{ Tobacco-Specific Nitrosamines (ng/cigarette) ${ }^{\boldsymbol{a}} \boldsymbol{c}$} \\
\hline Cigarette Products $^{\ddagger}$ & NAB \pm SD & NNK \pm SD & NAT \pm SD & NNN \pm SD & Total \pm SE \\
\hline Basic Blue 100s, HP & $9.9 \pm 0.7$ & $44.5 \pm 3.4$ & $57.4 \pm 8.9$ & $66.4 \pm 9.9$ & $178.2 \pm 4.8$ \\
Kent Golden, SP & $10.6 \pm 1.0$ & $35.9 \pm 4.5$ & $63.7 \pm 6.8$ & $66.7 \pm 11$ & $176.9 \pm 4.8$ \\
Camel Blue, HP & $9.4 \pm 1.5$ & $40.2 \pm 9.8$ & $65.2 \pm 10.0$ & $60.8 \pm 11.3$ & $175.5 \pm 5.7$ \\
Marlboro Silver 100s, HP & $8.8 \pm 1.0$ & $37.7 \pm 2.8$ & $62.7 \pm 5.4$ & $64.9 \pm 5.0$ & $174.1 \pm 3.7$ \\
Maverick Gold 100s, HP & $9.7 \pm 1.2$ & $43.8 \pm 7.7$ & $55.6 \pm 4.3$ & $64.5 \pm 13.9$ & $173.8 \pm 5.2$ \\
Marlboro Silver, HP & $9 \pm 0.6$ & $37.1 \pm 5.4$ & $61.7 \pm 5.9$ & $59.3 \pm 6.0$ & $167 \pm 4.2$ \\
Misty Blue Sims, HP & $8 \pm 0.7$ & $41.3 \pm 3.3$ & $51.5 \pm 3.7$ & $57.2 \pm 6.2$ & $158 \pm 3.7$ \\
Capri Magenta SS, HP & $8.8 \pm 1.1$ & $33.2 \pm 6.2$ & $60 \pm 4.9$ & $56 \pm 8.6$ & $158 \pm 4.6$ \\
Salem Silver 100s, HP & $7.8 \pm 1.7$ & $34.2 \pm 7.2$ & $49.3 \pm 11.6$ & $51.6 \pm 12.6$ & $142.9 \pm 5.8$ \\
Doral Silver 100s, HP & $6.9 \pm 0.6$ & $40.2 \pm 3.6$ & $41.8 \pm 5.4$ & $46.3 \pm 5.7$ & $135.3 \pm 3.9$ \\
True Silver, SP & $7.8 \pm 1.0$ & $19.3 \pm 2.7$ & $44.1 \pm 3.9$ & $51.8 \pm 5.4$ & $122.4 \pm 3.6$ \\
NOW Gold 100s, SP & $6.6 \pm 0.6$ & $23.2 \pm 4.1$ & $33.3 \pm 3.8$ & $31.8 \pm 5.1$ & $94.9 \pm 3.7$ \\
American Spirit Blue, HP & $b .2 \pm 0.9$ & $21.4 \pm 6.5$ & $23.8 \pm 3.8$ & $17.2 \pm 2.5$ & $66.5 \pm 3.7$ \\
Carlton White 100s, HP & $4.5 \pm 0.2$ & $13 \pm 1.7$ & $18.6 \pm 2.4$ & $18.6 \pm 3.6$ & $54.8 \pm 2.8$ \\
2R4F & $12.9 \pm 1.1$ & $115.6 \pm 8.7$ & $119 \pm 8.5$ & $133.1 \pm 12.5$ & $380.6 \pm 17.5$ \\
\hline
\end{tabular}

NAB, N-nitrosoanabasine; NNK, 4-(methylnitrosamino)-1-(3-pyridyl)-1-butanone; NAT, N-nitrosoanatabine; and NNN, N-nitrosonornicotine; Total, (Sum of NNK, NAB, NAT, and NNN) (ng/cigarette); B\&H, Benson and Hedges; HP, Hard Pack; SP, Soft Pack; SD, Standard deviation;

${ }^{a} \mathrm{~N}=7$-replicate measurements; SE, Standard error;

$b_{100 \%}$ Flue-cured tobacco;

${ }^{c}$ American blend cigarette products 


\section{Table 3}

Levels of TSNAs in mainstream smoke of domestic cigarettes tested with the Canadian Intense machinesmoking regimen. The cigarettes are rank ordered from highest to lowest total TSNA yield.

Tobacco-Specific Nitrosamines (ng/cigarette) ${ }^{a}{ }^{c}$

\begin{tabular}{|c|c|c|c|c|c|}
\hline Cigarette Products & $\mathbf{N A B} \pm \mathbf{S D}$ & $\mathrm{NNK} \pm \mathrm{SD}$ & NAT \pm SD & $\mathbf{N N N} \pm \mathbf{S D}$ & Total \pm SE \\
\hline Winston Red 100s, HP & $41.4 \pm 1.9$ & $245.9 \pm 21$ & $291.7 \pm 16.3$ & $323.3 \pm 22.6$ & $902.3 \pm 35$ \\
\hline Marlboro Red 100s, HP & $32.7 \pm 3.2$ & $167.6 \pm 21.1$ & $272.3 \pm 33.8$ & $262.3 \pm 29.4$ & $734.9 \pm 49.7$ \\
\hline Marlboro Green, HP & $27.1 \pm 2.3$ & $166.3 \pm 10.7$ & $259.4 \pm 13.2$ & $239.9 \pm 16.8$ & $692.7 \pm 23.9$ \\
\hline Marlboro Red, SP & $30.7 \pm 3.7$ & $159.6 \pm 14.8$ & $248.7 \pm 17.0$ & $249.7 \pm 28.4$ & $688.7 \pm 36.3$ \\
\hline Winston Red, HP & $32.6 \pm 1.8$ & $179.1 \pm 3.7$ & $230.4 \pm 16.3$ & $240.7 \pm 15.2$ & $682.8 \pm 22.7$ \\
\hline Marlboro Red 100s, SP & $33 \pm 1.7$ & $143.7 \pm 19.3$ & $253.3 \pm 21.6$ & $242.9 \pm 33.8$ & $672.9 \pm 44.7$ \\
\hline B\&H Green 100s, HP & $29.6 \pm 2.3$ & $144.9 \pm 18.7$ & $240.6 \pm 10,9$ & $241.7 \pm 25.9$ & $656.9 \pm 33.8$ \\
\hline Salem Green, HP & $29.2 \pm 3.2$ & $148.7 \pm 22.9$ & $245.7 \pm 30.3$ & $231.4 \pm 26.1$ & $654.9 \pm 46.3$ \\
\hline Marlboro Red Label, HP & $28.8 \pm 4.0$ & $146.7 \pm 17.9$ & $238.4 \pm 19.8$ & $224.6 \pm 21$ & $638.6 \pm 34.1$ \\
\hline Winston Gold, HP & $29.9 \pm 2.8$ & $166.6 \pm 14.8$ & $202.1 \pm 32.5$ & $223.9 \pm 28.9$ & $622.5 \pm 46.1$ \\
\hline Marlboro Red, HP & $27.9 \pm 3.9$ & $136.9 \pm 8.9$ & $232 \pm 14.9$ & $220 \pm 15.9$ & $616.7 \pm 23.6$ \\
\hline Newport Green 100s, HP & $27.7 \pm 3.2$ & $109.9 \pm 19.5$ & $204.9 \pm 11.8$ & $250.9 \pm 25.1$ & $593.3 \pm 34$ \\
\hline Basic Green 100s, HP & $24.6 \pm 2.2$ & $156.9 \pm 17.7$ & $194.6 \pm 22.4$ & $207.4 \pm 24.9$ & $583.4 \pm 38.1$ \\
\hline Marlboro Gold 100s, HP & $27.7 \pm 4.5$ & $123.14 \pm 10.4$ & $215.3 \pm 15.5$ & $205.6 \pm 21.1$ & $571.6 \pm 28.2$ \\
\hline USA Gold 100s, SP & $24.7 \pm 2.4$ & $124 \pm 11.6$ & $204.9 \pm 20.6$ & $215.1 \pm 32.8$ & $568.9 \pm 40.5$ \\
\hline Basic Gold 100s, SP & $25.2 \pm 1.6$ & $134 \pm 19.5$ & $183 \pm 13.2$ & $219.9 \pm 16.8$ & $562 \pm 28.9$ \\
\hline Marlboro Gold 100s, SP & $25.8 \pm 1.9$ & $123 \pm 15.4$ & $205.9 \pm 18.5$ & $197.4 \pm 16.6$ & $552.1 \pm 24.3$ \\
\hline Newport Green, SP & $24.8 \pm 2.6$ & $103.4 \pm 14.3$ & $186.6 \pm 17.1$ & $237 \pm 28.5$ & $551.7 \pm 36.3$ \\
\hline Basic Gold 100s, HP & $24.7 \pm 2.8$ & $142 \pm 10.1$ & $187.7 \pm 24.1$ & $193.1 \pm 17.5$ & $547.6 \pm 31.6$ \\
\hline Marlboro Gold, HP & $24.5 \pm 1.1$ & $115 \pm 17.5$ & $196 \pm 18.4$ & $206.1 \pm 38.4$ & $541.6 \pm 46.1$ \\
\hline Newport Green, HP & $25.1 \pm 2.9$ & $101.6 \pm 18.7$ & $186.7 \pm 17.1$ & $221.1 \pm 16$ & $534.5 \pm 30.0$ \\
\hline True Silver, SP & $25.8 \pm 2.8$ & $74.9 \pm 11.3$ & $192 \pm 13.7$ & $234.9 \pm 21.1$ & $527.6 \pm 27.6$ \\
\hline B\&H Luxury 100s, SP & $25.4 \pm 2.5$ & $108.1 \pm 43.4$ & $191 \pm 10.4$ & $192.1 \pm 25.8$ & $516.7 \pm 51.7$ \\
\hline Salem Gold, HP & $24 \pm 1.3$ & $127.4 \pm 22.5$ & $180.4 \pm 17.8$ & $180.9 \pm 11$ & $512.6 \pm 30.7$ \\
\hline Marlboro Menthol Gold, HP & $20.6 \pm 1.7$ & $119 \pm 16.7$ & $185.9 \pm 17.7$ & $186.1 \pm 23.4$ & $511.6 \pm 33.9$ \\
\hline Merit Gold, SP & $22.9 \pm 1.4$ & $108.4 \pm 8.1$ & $190.7 \pm 7.4$ & $188.9 \pm 8.4$ & $510.9 \pm 13.9$ \\
\hline Salem Gold 100s, HP & $23 \pm 2.9$ & $138.1 \pm 25.1$ & $180 \pm 22.2$ & $167.9 \pm 20.8$ & $509 \pm 39.5$ \\
\hline Winston White 100s, HP & $24.3 \pm 2.3$ & $139.4 \pm 17.1$ & $158 \pm 8.3$ & $184.3 \pm 9.4$ & $506 \pm 21.4$ \\
\hline Basic Blue 100s, HP & $21.9 \pm 2.4$ & $129.4 \pm 13.5$ & $161.4 \pm 10.6$ & $185.6 \pm 8.1$ & $498.3 \pm 19.0$ \\
\hline Marlboro Gold, SP & $22.5 \pm 1.6$ & $105.5 \pm 11$ & $181.3 \pm 16.6$ & $179.7 \pm 23.8$ & $488.9 \pm 31.1$ \\
\hline Kool Green, HP & $21.8 \pm 1.6$ & $123.3 \pm 25.6$ & $182.3 \pm 20.1$ & $158.6 \pm 23.1$ & $486 \pm 40$ \\
\hline Kool Green, SP & $22.1 \pm 1.9$ & $116.7 \pm 10.2$ & $181.7 \pm 19.8$ & $156.7 \pm 27.4$ & $477.2 \pm 35.3$ \\
\hline Marlboro Silver 100s, HP & $21.5 \pm 2.7$ & $97.4 \pm 63.5$ & $175.7 \pm 13.3$ & $181.3 \pm 13.7$ & $475.8 \pm 66.4$ \\
\hline Parliament Blue, HP & $22.9 \pm 2.8$ & $101.2 \pm 34.5$ & $176.6 \pm 27$ & $170.6 \pm 26$ & $471.2 \pm 51$ \\
\hline Marlboro Silver, HP & $21.2 \pm 1.5$ & $95.3 \pm 26.7$ & $179.4 \pm 34.3$ & $175.1 \pm 20.2$ & $471 \pm 48.1$ \\
\hline Vantage Multicolor, SP & $21.1 \pm 2.6$ & $142.4 \pm 16.9$ & $153 \pm 114.7$ & $154.4 \pm 19.5$ & $470.9 \pm 29.8$ \\
\hline
\end{tabular}


Tobacco-Specific Nitrosamines (ng/cigarette) ${ }^{a}, c$

\begin{tabular}{llllll}
\cline { 2 - 5 } & \multicolumn{5}{c}{ Tobacco-Specific Nitrosamines (ng/cigarette) $\boldsymbol{a} \boldsymbol{c}$} \\
\hline Cigarette Products & NAB \pm SD & NNK \pm SD & NAT \pm SD & NNN \pm SD & Total \pm SE \\
\hline Maverick Gold 100s, HP & $22.1 \pm 1.8$ & $107 \pm 13.2$ & $163.4 \pm 19.8$ & $171.1 \pm 20.8$ & $463.7 \pm 31.6$ \\
VA Slim Gold, HP & $19.8 \pm 1.5$ & $107.6 \pm 8.5$ & $165.9 \pm 18.6$ & $156.9 \pm 13.6$ & $450.1 \pm 25$ \\
NOW Gold 100s, SP & $20.7 \pm 1.3$ & $95.7 \pm 11$ & $161 \pm 21.9$ & $152.8 \pm 10.5$ & $430 \pm 26.8$ \\
Carlton White 100s, HP & $21 \pm 1.6$ & $107.2 \pm 12.4$ & $154 \pm 13.8$ & $135 \pm 12.7$ & $417.2 \pm 22.6$ \\
Camel Filters, HP & $21.5 \pm 1.8$ & $90.6 \pm 20$ & $161.9 \pm 28.4$ & $140.1 \pm 31$ & $414.1 \pm 46.6$ \\
Pall Mall Blue, HP & $18 \pm 2.4$ & $113.1 \pm 10$ & $134.1 \pm 10.6$ & $145.6 \pm 15.6$ & $410.9 \pm 21.4$ \\
Capri Magenta SS-H & $19.5 \pm 1.5$ & $76.8 \pm 8.9$ & $166.6 \pm 22.3$ & $145.7 \pm 38.1$ & $408.6 \pm 45.1$ \\
Doral Gold, HP & $16.6 \pm 1.1$ & $140.1 \pm 32.6$ & $123.3 \pm 15.1$ & $128.6 \pm 27.6$ & $408.6 \pm 45.3$ \\
Doral Silver 100s, HP & $17.3 \pm 3.5$ & $109.5 \pm 11.5$ & $132.8 \pm 16.4$ & $138.6 \pm 25$ & $398.1 \pm 32.1$ \\
Kent Golden, SP & $20.3 \pm 2.0$ & $71.1 \pm 12.4$ & $147.7 \pm 29.3$ & $150.7 \pm 26.6$ & $389.8 \pm 41.5$ \\
Camel Blue, HP & $19.1 \pm 2.2$ & $80.9 \pm 15.3$ & $151.9 \pm 14$ & $131.9 \pm 27.3$ & $383.6 \pm 34.3$ \\
Misty Blue Slims, HP & $16.2 \pm 1.7$ & $101 \pm 21.4$ & $124 \pm 22.9$ & $130.3 \pm 29.6$ & $371.4 \pm 43.2$ \\
Salem Silver 100s, HP & $18.5 \pm 1.2$ & $90.1 \pm 23.7$ & $133.7 \pm 24.5$ & $128.7 \pm 23.8$ & $371 \pm 41.6$ \\
American Spirit Blue HP $b$ & $6.5 \pm 1.0$ & $39.9 \pm 3.7$ & $44.3 \pm 2.5$ & $32.8 \pm 3.0$ & $123.5 \pm 5.5$ \\
2R4F & $27.8 \pm 2$ & $265.2 \pm 26.5$ & $226.5 \pm 17.8$ & $309.4 \pm 26.6$ & $828.9 \pm 49.9$ \\
\hline
\end{tabular}

NAB, N-nitrosoanabasine; NNK, 4-(methylnitrosamino)-1-(3-pyridyl)-1-butanone; NAT, N-nitrosoanatabine; and NNN, N-nitrosonornicotine; Total, (Sum of NNK, NAB, NAT, and NNN) (ng/cigarette); B\&H, Benson and Hedges; HP, Hard Pack; SP, Soft Pack; SD, Standard deviation;

${ }^{a} \mathrm{~N}=7$-replicate measurements; SE, Standard error;

$b_{100 \%}$ Flue-cured tobacco;

${ }^{c}$ American blend cigarette products 


\section{Table 4}

Percent difference (\%DIFF) of predicted TSNAs and total TSNA amounts derived from measured individual TSNA quantities

\begin{tabular}{|c|c|c|c|c|c|c|c|c|c|}
\hline & \multicolumn{3}{|c|}{ Tobacco Filler } & \multicolumn{3}{|c|}{ ISO smoking regimen } & \multicolumn{3}{|c|}{ CI Smoking regimen } \\
\hline TSNA & $\mathbf{R}^{2}$ & $\begin{array}{c}\text { DIFF } \\
(\%)\end{array}$ & $\begin{array}{l}95 \% \text { Confidence } \\
\text { Limits of DIFF } \\
(\%)\end{array}$ & $\mathbf{R}^{2}$ & DIFF (\%) & $\begin{array}{l}\text { 95\% Confidence } \\
\text { Limits of DIFF } \\
(\%)\end{array}$ & $\mathbf{R}^{2}$ & DIFF (\%) & $\begin{array}{l}95 \% \text { Confidence } \\
\text { limits of DIFF } \\
(\%)\end{array}$ \\
\hline NNK & 0.56 & -2.6 & -24 to 19 & 0.82 & 4.2 & -24.6 to 33 & 0.64 & 4.6 & -15.9 to 25 \\
\hline NAB & 0.85 & -0.2 & -10.2 to 10 & 0.93 & 7.4 & -14.8 to 29.5 & 0.93 & 3.5 & -8.9 to 15.8 \\
\hline NAT & 0.61 & -0.6 & -9.8 to 8.6 & 0.96 & -0.3 & -16.3 to 15.6 & 0.92 & 1.9 & -11.9 to 15.7 \\
\hline NNN & 0.89 & 0.2 & -11 to 11.4 & 0.95 & 4.3 & -7.9 to 16.6 & 0.98 & 2.7 & -7.2 to 12.5 \\
\hline
\end{tabular}

ISO, International Organization of Standards machine-smoking regimen; CI, Health Canada Intense machine-smoking regimen; $\mathrm{R}^{2}$, Coefficient of Determination; DIFF $(\%)=[($ sum of measured quantities of all four TSNAs -Predicted Total TSNAs $) /$ sum of measured quantities of all four TSNAs] x 100 . 